\title{
Multi-Angle Welding Jig
}

\author{
Ernie A. Daitao, D.I.T. \\ Associate Professor \\ Iloilo Science and Technology University \\ Philippines
}

\begin{abstract}
This developmental study was conducted to design, fabricate, and evaluate the new features of the Multi-Angle Welding Jig (MAWJ) so that can easily set, securely and automatically clamp and releases workpieces allowing high degree freedom of movement, fast and accurate welding procedure. Specifically, this study focused on the clamping performance of the device in holding different sizes and shapes of the pipes and bars driven by 15 psi pneumatic pressure connected to a compressor. Then, the study also focused on the adjustable clamps and jaws that adjusted could be adjusted in multiple angles of $30^{\circ}, 45^{\circ}, 60^{\circ}, 90^{\circ}$, and $180^{\circ}$. Moreover, the data recorded concerning time showed that the device was quick in clamping and releasing and when the user applied to weld or tacking it can finish the whole process in seconds.
\end{abstract}

Keywords: Multi-Angle, Weld, Axis, Jig, Clamps, Hold, Plurality, Jaws, Legs, Pneumatic, Cylinder, Locking, Ferrous

\section{Introduction}

Welding is a conventional method used in joining metals, but a device known as the jig accompanies it. Griffin (1994) stressed that it is the process of joining pieces of metal together by heating the edge until they begin to melt and then pressing them together. Trewhella (1939) also added that such a process, a jig is needed to set, clamp, and release the metal after applying to weld. Hesse (2001) confirmed the assembly of parts of the structure has a high demand, especially in the metal industry working on jigs and fixtures.

The development of the MAWJ was a product of the ambiguities and problems of the previous design. The jig developed by De Vogt (1954) can perform clamping and is manually operated using a screw. Another jig developed by Tierney (1955) used to screw in clamping the material using a rotatable screw to secure the inner of the clamping bar rotatably but is also manually operated. The jig developed by Wong (2005) has a 3-axis workpieces by providing X, $\mathrm{Y}$, and $\mathrm{Z}$ clamping surfaces but manually operated even though a quick-acting button offers it. Anti-spatter substance (phosphate) is applied to the parts of the jig to make it spatter free. Its head is moving in or out but is done individually by turning the corresponding threaded shaft clockwise or counterclockwise to adjust for different sizes of workpieces.

\section{Synthesis}

The identified state-of-the-art for jigs have limitations such as enhanced wear and tear of the gadget due to the frequent use of screw threads that will eventually result in inaccuracy in clamping. Furthermore, the use of an anti-spatter substance (phosphate) is environmentally hazardous. All technologies reviewed manually operated, thus using them would be time-consuming and needs specialized skills in the operation. Because of the limitations of the abovementioned prior arts, the study conceived.

\section{Research Significance}

The MAWJ is a device that can easily set, securely and automatically clamp and releases workpieces allowing a high degree of freedom of movement, fast and accurate welding procedure. It addresses the limitations of the state-of-the-art of jigs such as rapid wear and tear, inaccuracy in clamping and more prolonged period of operations due to it is being manually operated nature and the use of anti-spatter substance (phosphate) which is environmentally hazardous thus, resulting to an effective, efficient and ecologically friendly clamping operation in welding processes.

\section{Purpose of the Research}

Generally, this study aimed to design and fabricate multi-angle welding jig.

Specifically, this study aimed to:

1. design and fabricate a multi-angle welding jig, and

2. evaluate the operating performance of the device as to the accuracy of angle and clamping time. 


\section{Description of the Device}

\subsection{Design Criteria}

\subsubsection{Base Plate and Clamping Materials}

According to the National Institute of Technology Calicut (2017), jigs and fixtures made of the variety of materials, some of which can be hardened to resist wear. First is the high-speed steel which used for cutting tools like drills, reamers and milling cutters. Second is the die steel, which applied for press tools that contain $1 \%$ carbon, 0.5 to $1 \%$ tungsten and fewer quantities of silicon and manganese. The third is the carbon steels used for standard cutting tools. Lastly is the collet steel for spring steels containing $1 \%$ carbon, $0.5 \%$ manganese and less of Silicon. While the base plate made of $25 \mathrm{~mm}$ thick medium carbon steel coated with brass to act as an anti-spatter agent. All the clamping jaws were also anti-spatter material. The support materials were sturdy steel able to resist heat delivered by the welding machine during the process. The clamping jaws were left and right movable fixed jaw and the vertical jaws design with V-groove as teeth to hold the workpieces firmly when clamping.

Besides, the American Iron and Steel Institute (AISI) and Society of Automotive Engineers (SAE) International, as a standard organization were both involved in efforts to standardize such a numbering system for steels. In the present study, medium carbon steel used as a base plate and clamping materials. This material contained approximately 0.3$0.6 \%$ carbon content which balances ductility and strength and had excellent wear resistance; used for large parts, forging automotive components. It is in this context that the multi-angle welding jig perfectly complimented using carbon steel for the reason that the during the welding process if the carbon percentage content rose the iron can become harder and stronger through heat treating and however it became less ductile. In this regard, the duplication of the workpieces would not compromise because it reduces the weldability due to the higher carbon content that lowered the melting point.

\subsubsection{Clamping Pressure}

The clamping pressure also based on the industry. Hesse (2001) in his book entitled "Clamping with Compressed Air and Vacuum," the required psi for a pneumatically driven clamp is 10 to 20 . Between the given requirements the researcher designed the present study in $15 \mathrm{psi}$ to attain quality force to clamp the workpieces in place without damaging or distorting the materials. Standards also have great significance in pneumatics. Rules mean harmonization (standardization) for general use. Standards promote rationalization; they contribute to the safety of personnel and equipment, for example by means of internationally specified and universally comprehensible characteristics, and advance quality assurance through the use of specified quality characteristics and acceptable conditions - the idea established by the International Standardization Organization (ISO), European standards, German DIN standards, and International Electrotechnical Commission (IEC).

\subsubsection{The Adjustable and Movables Clamping Jaws}

The movable clamping jaws designed with checkered grooves to counter the clamping pipes and bars. These jaws were primarily used to clamp and to adjust in the back angles, $30^{\circ}, 45^{\circ}, 60^{\circ}, 90^{\circ}$, and $180^{\circ}$ provided with threaded locks and levers for comfortable gripping when losing and tightening the clamps. The device also designed to provide $180^{\circ}$ angle for freedom of movement during the welding process for the worker to see the joining process and the allowable area for the welding apparatus to work with the workpieces. Furthermore, the base plate also supported the pneumatic cylinder that drove the clamps.

\subsection{Limitations and Constraints}

This study was limited to the multi-angle welding jig on any angle ranging from $30^{\circ}$ to $180^{\circ}$ concerning setting, clamping, and releasing the workpieces after welding process that would hold any sizes and shapes of the pipes and bars. The researcher used black iron (BI) pipes in the actual testing. For the pipes, the minimum material was schedule 20 with a diameter of $1 "$ to $4 "$. For the bars the minimum was $1, "$ and the maximum was $4 "$ - the device driven by a pressure of 15 psi to clamp pipes and bars. The actual testing done in five (5) trials using a schedule $20 @ 1 " \varnothing$ pipes by one person to eliminate biases during the test. The testing of the device based on the accuracy of the angles and clamping time.

\subsection{Design Preparation, Testing, and Revisions}

The MAWJ assembled at Iloilo Science and Technology University (ISAT U), La Paz, Iloilo City. The design innovated based on the study of Wong (2005).

The nearest priors arts presented realized to have some disadvantages which the basis of the researcher to conduct a further study specifically on the setting, clamping, and releasing the workpieces after welding concerning the accuracy of angles and clamping time. The technical evaluation was done at the ISAT U in February 2017 together with the panel 40 
of experts coming from the academe and industry sectors composed of engineers, instructors, and professors, shop owners, welders and machinists in the city and province. Suggestions and recommendations were applied in the device to enhance its performance further.

The device made using locally made materials available in the vicinity of the researcher. In designing the multi-angle welding clamp, the researcher selected materials that could withstand repetitive activities, resist heat and would not absorb electrical current discharged by the welding machine during the work. The main activities involved using the device was setting, clamping, and releasing the workpieces after the welding process. The quick clamping and releasing of the workpieces were the main features of the invention that could be done in seconds, wherein more outputs were expected to produce in a matter of time. Because it was multi-angled, the clamping jaws were adjustable to the angles of $30^{\circ}, 45^{\circ}, 60^{\circ}, 90^{\circ}$, and $180^{\circ}$ with the aid of a universal protractor to determine its accuracy, and then locked them with levers for comfortable gripping when losing and tightening the jaws. When welding the workpieces, enough space was provided by having a $180^{\circ}$-angle for freedom of movement to the worker and the welding apparatus. The device was constructed based on the blueprints designed by the researcher. The working drawings were made using an AutoCAD and Adobe Illustrator for the top, front, and end views, while in the pictorial illustrations, a 3-D Max and Photoshop were used to see the real materials of the device. A mock-up was made to see the whole picture and the components of the device.

Figures 1, 2 and 3 show the proposed design of a Multi-Angle Welding Jig in its three-view drawing and its pictorial drawing with labeled parts while Figure 4 shows its Isometric view.

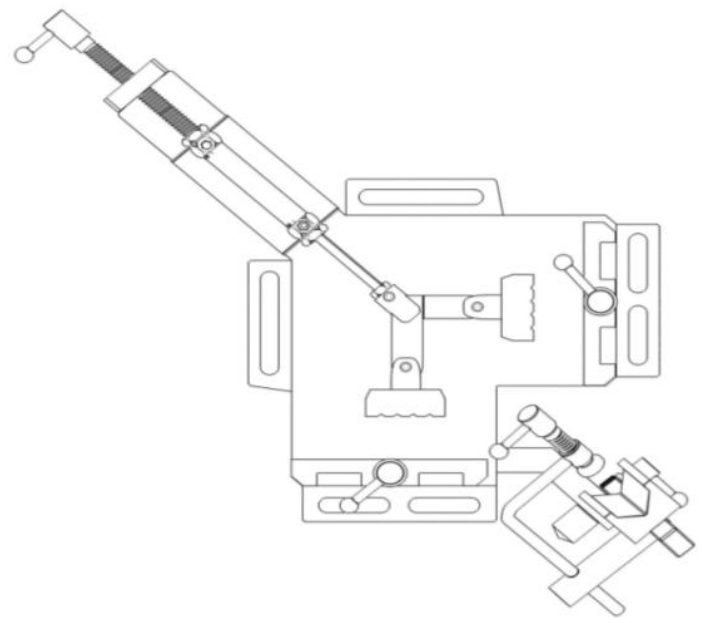

Figure 1: Top View of the Multi-Angle Welding Jig.

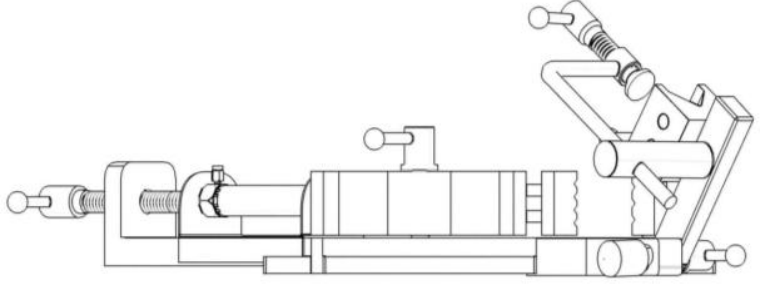

Figure 2: Front View of the Multi-Angle Welding Jig.

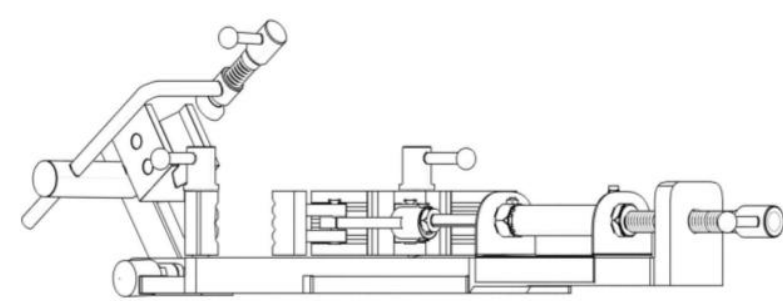

Figure 3: End View of the Multi-Angle Welding Jig. 


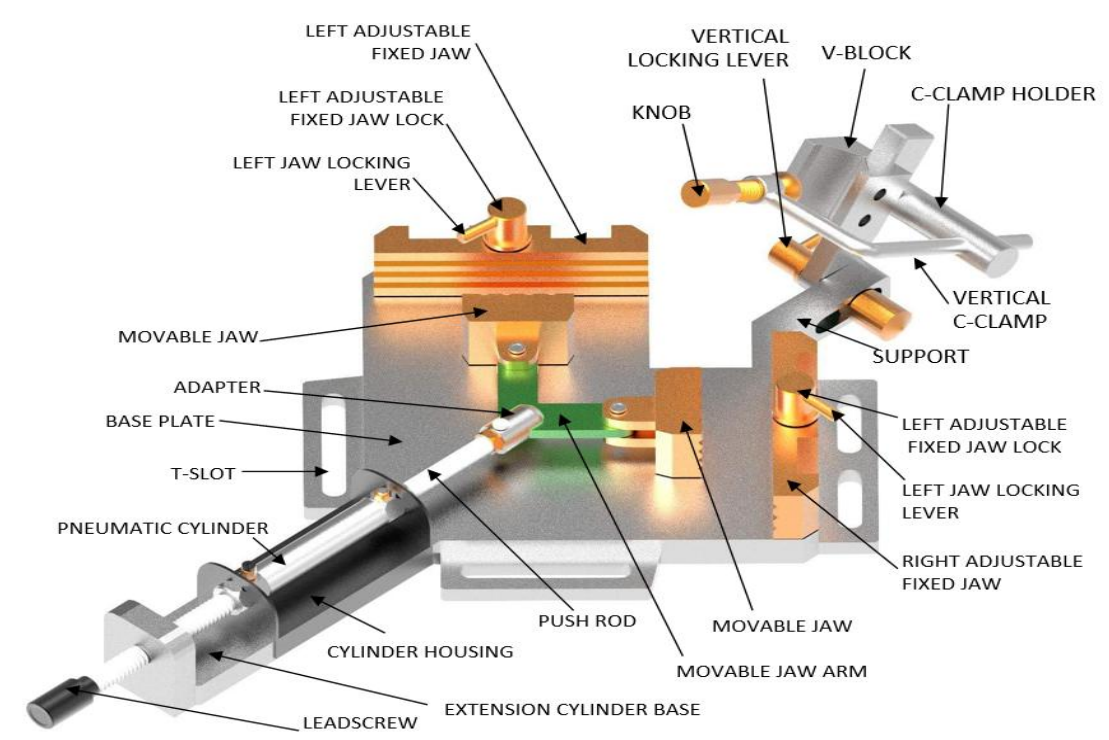

Figure 4: The Proposed Design of a Multi-Angle Welding Jig in Isometric View.

\section{Results and Discussions}

\subsection{Technology}

This device is related to the pneumatic driven MAWJ that can easily set and automatically clamp and releases workpieces allowing a high degree of freedom of movement, fast and accurate welding procedure. MAWJ commonly used in the fabrication of the fixtures for machines, frameworks, and other structures. The principle of operation of the said device is the same as the other clamping device found in the market. It functions as multi-angle welding jig by adjusting the angle of the clamp in different angles and can also accommodate different sizes and shapes of pipes and bars.

The clamp or the jaw is provided with a unique lock to set on the desired angle. The use of the left-fixed and rightfixed adjustable jaw, and the vertical C-clamp or the Z-axis are advantageous when making three (3) pieces of the workpiece for joining. The pneumatic device set to 15 psi by $1 / 2$ HP compressor for quick clamping method. The saving time for this kind of work is a significant factor for production. Another feature of the invention is the freedom of movement when welding or tacking the workpieces. The design of the MAWJ done in consideration with the Occupational Ergonomics Handbook (1998), which is the science that deals with designing and arranging things so that people can use them quickly and safely. Also, Design of the clamping jig done according to the modern trend at clamping devices (Němec, 2015).

Another embodiment found in the present study is the extended base plate that provides the location of the pneumatic cylinder for driving the movable jaws to clamp the pipes and bars. It also equipped with leadscrew for adjusting the cylinder. The new technologies mentioned has surpassed the invention of Wong with a Patent No. of US6,860,475 B2.

\subsection{Brief Description of the Drawing}

Mentioned above were the objects of the present technology which may be seen in the drawing illustrated:

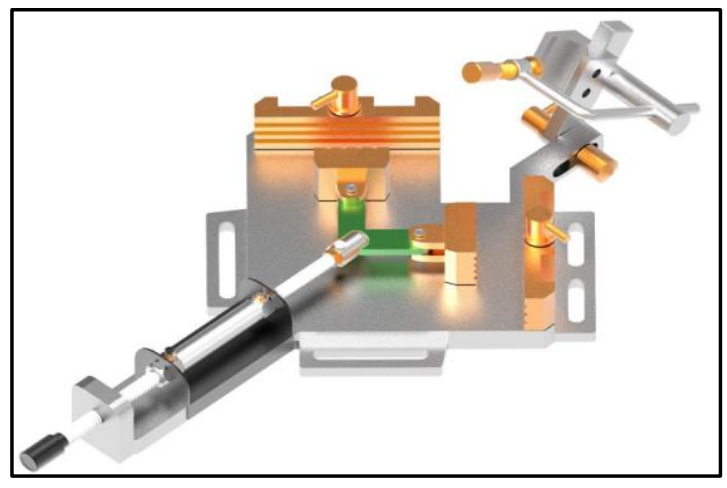

Figure 6: Rendered Pictorial Drawing of the Multi-angle Welding Jig

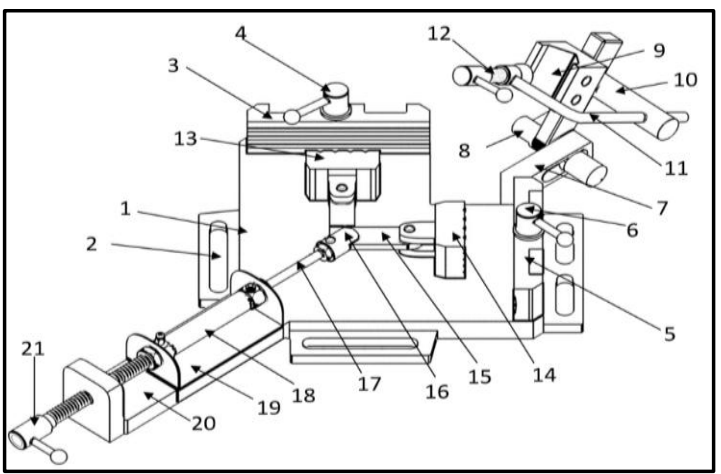

Figure 7: Components of the Multi-angle Welding Jig. 

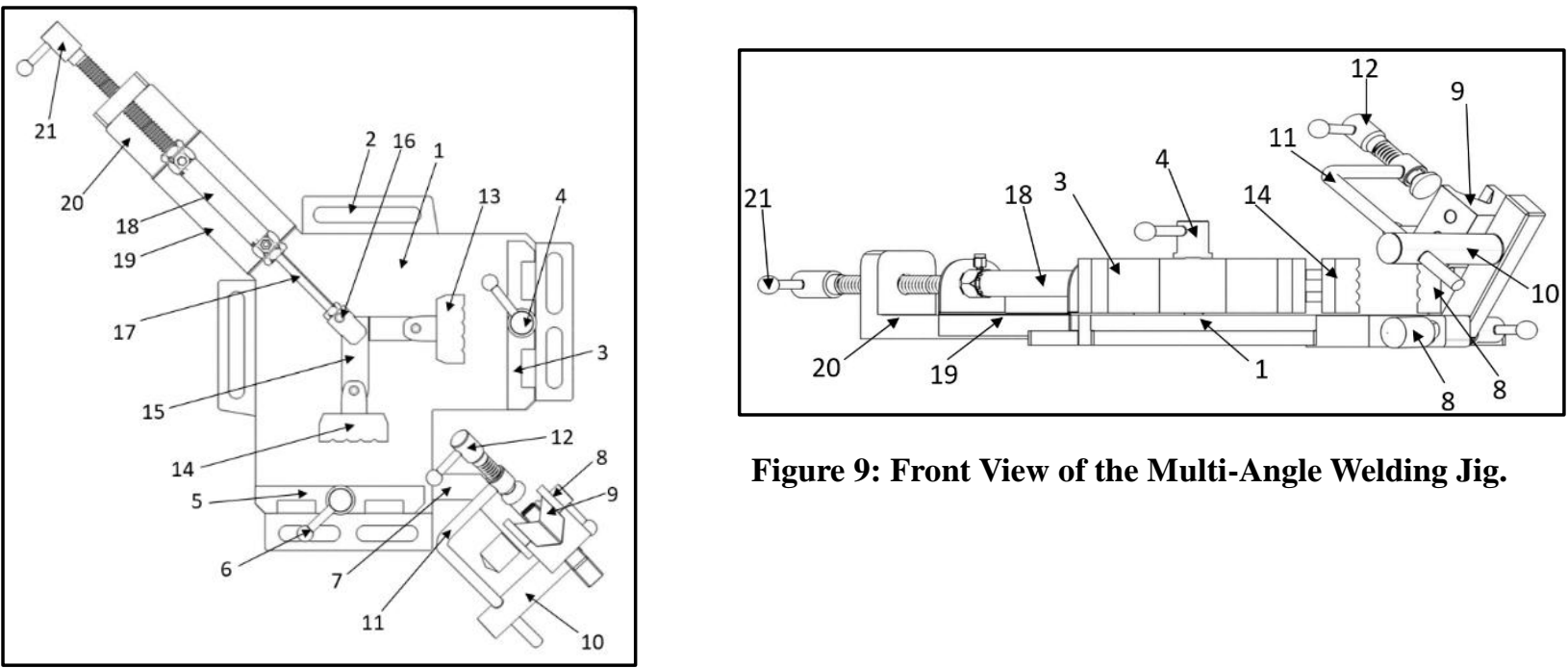

Figure 9: Front View of the Multi-Angle Welding Jig.

Figure 8: Top View of the Multi-angle Welding Jig.

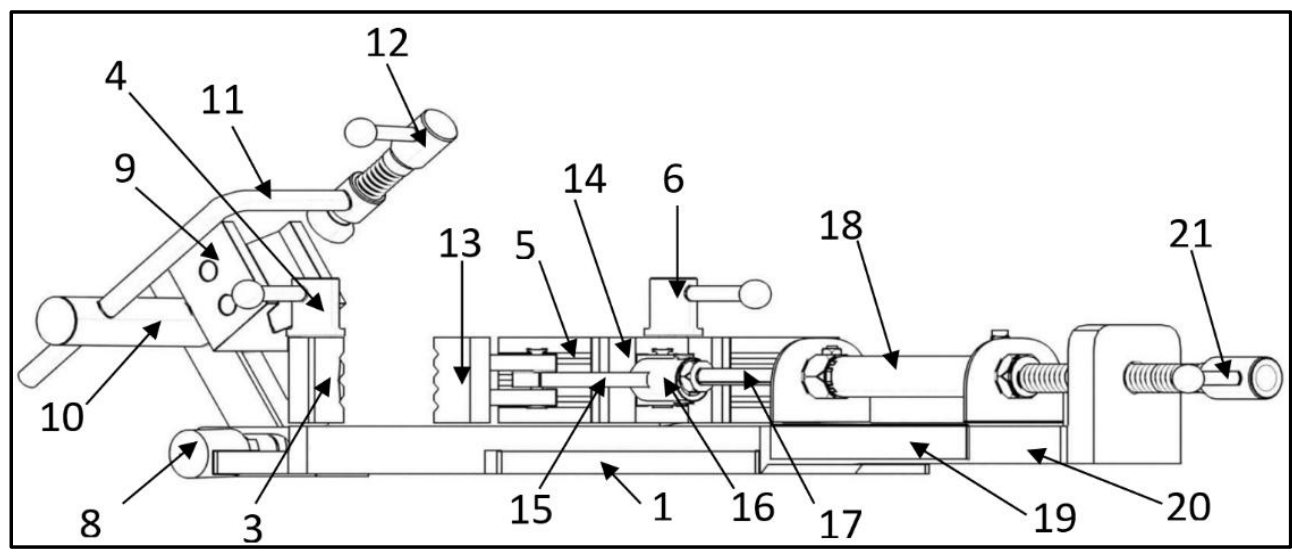

Figure 10: End View of the Multi-angle Welding Jig.

\subsection{Detail Description of Technology}

Referring now to the drawing of the technology as disclosed in Figure 6-10, illustrated the innovated components of the MAWJ.

As shown in the (Fig. 7) the various components of the present technology are the base plate (1) is provided with the tslot (2) for fastening on the working bench (not shown). The base plate (1) is rotatably attached to the lower position of the left jaw (3) by a locking mechanism (4). The right jaw (5) rotatably connected to the lower portion of the base plate (1) by a locking mechanism (6). The support (7) is attached to the base plate (1) by a locking mechanism (8) wherein the V-block (9) is adjustably connected to the locking mechanism (8). The V-block (9) is attached to the base plate (1) used to hold and secure the pipe with rotatably securely C-clamp holder (10) for vertical C-clamp (11) equip with a locking mechanism (12). The base plate (1) provided with an extension cylinder base assembly (20) for the cylinder base housing (19) which is adjustably attached to the extension cylinder base (20). The cylinder base housing (19) housed the pneumatic cylinder (18) with push rod (17) connected permanently to the adapter (16) that is permanently adjustably attached to the left jaw (13) and right jaw (14) is moving above the base plate (1) to clamp on the left jaw (3) and right jaw (5). The pneumatic cylinder (18) is adjustable by a leadscrew (21).

The operation of the multi-angle welding jig was simple. Before the operation of the device check first the compressor (not illustrated) if the pressure is 15 psi and then proceed to the process of the multi-angle welding jig. First, check the pneumatic cylinder (18) if it is pushing the push rod (17) wherein the left jaw (13) and right jaw (14) is attached in it to set and clamp the metal. Second, adjust the leadscrew (21) to achieve the desired distance for left jaw (13) and right jaw (14) to set and clamp the pipes and bars and if the distance of the left jaw (13) and left jaw (14) enough to set and clamp the metal then apply welding to the pipes and bars. It is on this point where multiple joining processes are done. 
Third, after applying to weld, press the release button (not illustrated) to release the clamps $(13,14)$ and check the output. Fourth, to perform another job repeat second step. Switch off the button (not illustrated) if power button if not in use. Keep the device in a safe place for safe keeping.

\subsection{Interpretation of the Data}

The technical evaluation is done at the ISAT U in February 2017 together with the panel of experts coming from the academe and industry sectors composed of engineers, instructors, and professors, shop owners, welders and machinists in the city and province.

The device tested based on the clamping of the device as to the angles and time of the pipes of different sizes. During the actual testing schedule, $20 @ 1 " \varnothing$ pipes used as material because they were round in nature. With this method, the present invention tested in its performance in clamping and tested the clamping pressure whether the materials would be damaged or not, for it was the thinnest regarding thickness in pipes. The joint angles used in the joining of workpieces were $30^{\circ}, 45^{\circ}, 60^{\circ}, 90^{\circ}$, and $180^{\circ}$ - the percentage of error set by the researcher allowed in the testing of the accuracy of the angles. Zhang \& Hocken (2008) suggests that the angle measurements are of great importance in machine calibration. The reason is due to large Abbe offsets, and long travel at machine tools and measuring machines the angular motion errors and out-of-squareness of the guideways often contribute much more to the total error budget than the linear positioning errors and straightness errors. During the test of clamping time using 15 psi pressure, quick clamping recorded the maximum time of 15.00 seconds. All of the evaluators strongly agreed that the device was accessible when welding the workpieces.

The schedule $20 @ 1 " \varnothing$ material used in the test five times and visually evaluated and recorded the instrument designed by the researcher. A universal protractor used to determine the accurateness of the angle, and a stopwatch used to determine the time spent in the entire process (set, clamp, and release after welding). Furthermore, the quick clamping and release gave an edge to the MAWJ during the trials. Carlson (2011) pointed out that the percentage of error is the actual data subtracted by the standard data and divided by the standard data.

Table 1: Clamping of Schedule 20 @ 1" Ø Pipe Concerning Angle and Time Using the Device Set at a 30 ${ }^{\circ}$-Angle

\begin{tabular}{|c|c|c|c|}
\hline \multirow{2}{*}{ Trials } & \multicolumn{2}{|c|}{$\mathbf{3 0}^{\circ}$ Angle } & \multirow{2}{*}{ Time (sec) } \\
\cline { 2 - 3 } & Actual & Deviation & \\
\hline 1 & 30.00 & 0.00 & 15.00 \\
\hline 2 & 30.00 & 0.00 & 14.00 \\
\hline 3 & 30.00 & 0.00 & 12.00 \\
\hline 4 & 30.00 & 0.00 & 13.00 \\
\hline 5 & 30.00 & 0.00 & 11.00 \\
\hline Mean & $\mathbf{3 0 . 0 0}$ & 0.00 & $\mathbf{1 3 . 0 0}$ \\
\hline$\%$ of error & 0.00 & 0.00 & \\
\hline
\end{tabular}

As shown in Table 1 the result of the clamping of the device as to angle and time of the schedule $20 @ 1$ " $\varnothing$ pipe using $30^{\circ}$, in five (5) trials of the device, recorded a mean of $30^{\circ}$ accuracy. As to clamping time, the invention recorded a mean of 13.00 seconds. The device is accurate concerning clamping.

Table 2: Clamping of Schedule 20 @ 1" Ø Pipe Concerning Angle and Time Using the Device Set at a $45^{\circ}$-Angle

\begin{tabular}{|c|c|c|c|}
\hline \multirow{2}{*}{ Trials } & \multicolumn{2}{|c|}{$\mathbf{4 5}^{\circ}$ Angle } & \multirow{2}{*}{ Time (sec) } \\
\cline { 2 - 3 } & Actual & Deviation & \\
\hline 1 & 44.75 & 0.25 & 14.00 \\
\hline 2 & 44.83 & 0.17 & 14.00 \\
\hline 3 & 45.00 & 0.00 & 12.00 \\
\hline 4 & 45.00 & 0.00 & 12.00 \\
\hline 5 & 45.00 & 0.00 & 11.00 \\
\hline Mean & $\mathbf{4 4 . 9 2}$ & $\mathbf{0 . 0 8}$ & $\mathbf{1 2 . 6 0}$ \\
\hline \% of error & $\mathbf{- 0 . 1 8}$ & & \\
\hline
\end{tabular}

As shown in Table 2, the result of the clamping of the device as to angle and time of the schedule $20 @ 1$ " $\varnothing$ pipe using $45^{\circ}$, the trials of the device recorded a mean of $44.92^{\circ}$ accuracy, and as to clamping time, the invention recorded a mean of 12.60 seconds. MAWJ is accurate concerning clamping. 
Table 3: Clamping of Schedule 20 @ 1" Ø Pipe Concerning Angle and Time Using the Device Set at a $60^{\circ}-$ Angle

\begin{tabular}{|c|c|c|c|}
\hline \multirow{2}{*}{ Trials } & \multicolumn{2}{|c|}{$\mathbf{6 0}^{\circ}$ Angle } & \multirow{2}{*}{ Time (sec) } \\
\cline { 2 - 3 } & Actual & Deviation & \\
\hline 1 & 60.00 & 0.00 & 15.00 \\
\hline 2 & 60.00 & 0.00 & 14.00 \\
\hline 3 & 60.00 & 0.00 & 13.00 \\
\hline 4 & 60.00 & 0.00 & 12.00 \\
\hline 5 & 60.00 & 0.00 & 11.00 \\
\hline Mean & $\mathbf{6 0 . 0 0}$ & 0.00 & $\mathbf{1 3 . 0 0}$ \\
\hline \% of error & 0.00 & 0.00 & \\
\hline
\end{tabular}

As shown in Table 3, the result of the clamping of the device as to angle and time of the schedule 20 @ 1 " Ø pipe using $60^{\circ}$, the trials of the device recorded a mean of $60^{\circ}$ accuracy, and as to clamping time, the invention recorded a mean of 13.00 seconds. Based on the observation of the panel of experts the device is accurate concerning clamping.

Table 4: Clamping of Schedule 20 @ 1" Ø Pipe Concerning Angle and Time Using the Device Set at a 90 ${ }^{\circ}$ Angle

\begin{tabular}{|c|c|c|c|}
\hline \multirow{2}{*}{ Trials } & \multicolumn{2}{|c|}{$\mathbf{9 0}^{\circ}$ Angle } & \multirow{2}{*}{ Time (sec) } \\
\cline { 2 - 3 } & Actual & Deviation & \\
\hline 1 & 90.00 & 0.00 & 14.00 \\
\hline 2 & 89.75 & 0.25 & 14.00 \\
\hline 3 & 90.00 & 0.00 & 13.00 \\
\hline 4 & 90.00 & 0.00 & 10.00 \\
\hline 5 & 90.00 & 0.00 & 10.00 \\
\hline Mean & $\mathbf{8 9 . 9 5}$ & $\mathbf{0 . 0 5}$ & $\mathbf{1 2 . 2 0}$ \\
\hline \% of error & $\mathbf{- 0 . 0 6}$ & & \\
\hline
\end{tabular}

As shown in Table 4, the result of the clamping of the device as to angle and time of the schedule 20 @ 1 " Ø pipe using $90^{\circ}$, the trials of the device recorded a mean of $89.95^{\circ}$ accuracy, and as to clamping time, the invention recorded a mean of 12.20 seconds. The multi-angle welding jig is accurate concerning clamping.

Table 5: Clamping of Schedule 20 @ 1 " Ø Pipe Concerning Angle and Time Using the Device Set at a 180 ${ }^{\circ}$-Angle

\begin{tabular}{|c|c|c|c|}
\hline \multirow{2}{*}{ Trials } & \multicolumn{2}{|c|}{$\mathbf{1 8 0}^{\circ}$ Angle } & \multirow{2}{*}{ Time (sec) } \\
\cline { 2 - 3 } & Actual & Deviation & \\
\hline 1 & 180.00 & 0.00 & 13.00 \\
\hline 2 & 180.00 & 0.00 & 13.00 \\
\hline 3 & 180.00 & 0.00 & 13.00 \\
\hline 4 & 180.00 & 0.00 & 10.00 \\
\hline 5 & 180.00 & 0.00 & 10.00 \\
\hline Mean & $\mathbf{1 8 0 . 0 0}$ & 0.00 & $\mathbf{1 1 . 8 0}$ \\
\hline \% of error & 0.00 & 0.00 & \\
\hline
\end{tabular}

As shown in Table 5, the result of the clamping of the device as to angle and time of the schedule 20 @ 1 " Ø pipe using $180^{\circ}$, the trials of the device recorded a mean of $180^{\circ}$ accuracy, and as to clamping time, the invention recorded a mean of 11.80 seconds. The device is accurate regarding clamping.

The MAWJ device tested for precision regarding angles using a schedule $20 @ 1$ " $\varnothing$ pipe. The researcher set precision at $\pm 3 \%$ error and observations made for the five (5) trials of each set with the device set at $30^{\circ}, 45^{\circ}, 60^{\circ}, 90^{\circ}$, and $180^{\circ}$-angles. Table 6 shows the result. 
Table 6: Performances of the Device set at Different Angles Using a Schedule 20 @1" Ø Pipe

\begin{tabular}{|c|c|c|c|c|c|c|c|c|c|c|}
\hline \multirow{3}{*}{ Trials } & \multicolumn{2}{|c|}{$\mathbf{3 0}^{\circ}$ Angle } & \multicolumn{2}{c|}{$\mathbf{4 5}^{\circ}$ Angle } & \multicolumn{2}{c|}{$\mathbf{6 0}^{\circ}$ Angle } & \multicolumn{2}{c|}{$\mathbf{9 0}^{\circ}$ Angle } & \multicolumn{1}{|c|}{$\mathbf{1 8 0}^{\circ}$ Angle } \\
\cline { 2 - 12 } & $\begin{array}{c}\text { Actual } \\
\text { Measure }\end{array}$ & Deviation & $\begin{array}{c}\text { Actual } \\
\text { Measure }\end{array}$ & Deviation & $\begin{array}{c}\text { Actual } \\
\text { Measure }\end{array}$ & Deviation & $\begin{array}{c}\text { Actual } \\
\text { Measure }\end{array}$ & Deviation & $\begin{array}{c}\text { Actual } \\
\text { Measure }\end{array}$ & Deviation \\
\hline 1 & 30.00 & 0.00 & 44.75 & 0.25 & 60.00 & 0.00 & 90.00 & 0.00 & 180.00 & 0.00 \\
\hline 2 & 30.00 & 0.00 & 44.83 & 0.17 & 60.00 & 0.00 & 89.75 & 0.25 & 180.00 & 0.00 \\
\hline 3 & 30.00 & 0.00 & 45.00 & 0.00 & 60.00 & 0.00 & 90.00 & 0.00 & 180.00 & 0.00 \\
\hline 4 & 30.00 & 0.00 & 45.00 & 0.00 & 60.00 & 0.00 & 90.00 & 0.00 & 180.00 & 0.00 \\
\hline 5 & 30.00 & 0.00 & 45.00 & 0.00 & 60.00 & 0.00 & 90.00 & 0.00 & 180.00 & 0.00 \\
\hline Mean & $\mathbf{3 0 . 0 0}$ & 0.00 & $\mathbf{4 4 . 9 2}$ & $\mathbf{0 . 0 8}$ & $\mathbf{6 0 . 0 0}$ & 0.00 & $\mathbf{8 9 . 9 5}$ & $\mathbf{0 . 0 5}$ & $\mathbf{1 8 0 . 0 0}$ & 0.00 \\
\hline $\begin{array}{c}\% \text { of } \\
\text { error }\end{array}$ & 0.00 & 0.00 & $\mathbf{- 0 . 1 8}$ & & 0.00 & 0.00 & $\mathbf{- 0 . 0 6}$ & & 0.00 & 0.00 \\
\hline
\end{tabular}

The data shows that there were deviations in the measurements of the angle when the device was set at $45^{\circ}(\%$ of error $=-.18)$ and $90^{\circ}(\%$ of error $=-.06)$. There were no deviations when the device set at $30^{\circ}, 60^{\circ}$, and $180^{\circ}$. These results show that the deviations are within the precision level set by the researchers. Therefore, the device is precise and meets the researcher's standard.

Table 7: The Performances of the Device Regarding Time Using a Schedule 20 @ 1" Ø Pipe

\begin{tabular}{|c|c|c|c|c|c|c|}
\hline \multirow{2}{*}{ Trials } & $\mathbf{3 0}^{\circ}$ Angle & $\mathbf{4 5}^{\circ}$ Angle & $\mathbf{6 0}^{\circ}$ Angle & $\mathbf{9 0}^{\circ}$ Angle & $\mathbf{1 8 0}^{\circ}$ Angle & \multirow{2}{*}{ Mean } \\
\cline { 2 - 6 } & Time (sec) & Time (sec) & Time (sec) & Time (sec) & Time (sec) & \\
\hline 1 & 15.0 & 14.0 & 15.0 & 14.0 & 13.0 & 14.2 \\
\hline 2 & 14.0 & 14.0 & 14.0 & 14.0 & 13.0 & 13.8 \\
\hline 3 & 12.0 & 12.0 & 13.0 & 13.0 & 13.0 & 12.6 \\
\hline 4 & 13.0 & 12.0 & 12.0 & 10.0 & 10.0 & 11.4 \\
\hline 5 & 11.0 & 11.0 & 11.0 & 10.0 & 10.0 & 10.6 \\
\hline Mean & 13.0 & 12.6 & 13.0 & 12.2 & 11.8 & 12.5 \\
\hline
\end{tabular}

In terms of processing (setting, clamping, applying weld and releasing the pipe after welding) the table shows that in the five (5) trials, the average time to perform the process is $14.2,13.8,12.6,11.4$, and 10.6 seconds when set at $30^{\circ}$, $45^{\circ}, 60^{\circ}, 90^{\circ}$, and $180^{\circ}$-angle, respectively. The MAWJ can perform in an average time of 12.5 seconds only.

\section{Findings}

The findings of the study are as follows:

- The design and fabrication of the device data showed that there were deviations in the measurements of the angles when the device was set at $45^{\circ}(\%$ of error $=-.18)$ and $90^{\circ}(\%$ of error $=-.06)$, but there were no deviations when it set at $30^{\circ}, 60^{\circ}$, and $180^{\circ}$. These results showed that the deviations were within the precision level set by the researcher. The device précised and met the researcher's standard.

- In terms of process (setting, clamping, applying weld and releasing the pipe after welding) the table showed that in the five (5) trials the average time to perform the process was 14.2, 13.8, 12.6, 11.4, and 10.6 seconds when set at $30^{\circ}, 45^{\circ}, 60^{\circ}, 90^{\circ}$, and $180^{\circ}$-angle respectively.

\section{Conclusions}

Based on the findings, the following conclusions are as follows:

- The MAWJ was accurate in clamping when setting at $30^{\circ}, 45^{\circ}, 60^{\circ}, 90^{\circ}$ and $180^{\circ}$-angle using a schedule $20 @ 1 " \varnothing$.

- The MAWJ when setting at $30^{\circ}, 45^{\circ}, 60^{\circ}, 90^{\circ}$, and $180^{\circ}$-angle, could perform the clamping of pipe schedule $20 @ 1 "$ $\varnothing$ in 13.00 seconds, 12.60 seconds, 13.00 seconds, 12.20 seconds, and 11.80 seconds, respectively.

\section{Recommendations}

By the findings and conclusions of this study, the following recommendations are offered:

- Utilize the MAWJ for industrial manufacturing of parts, especially for jig and fixtures particularly on pipe fittings.

- Adopt the device for the metal construction industry on the actual construction of projects such as metal frame structure in different angles.

- Introduce the device in the mechanical technology class to experience its performance. Furthermore, used it for actual welding and fabrication of the projects in the mechanical shop to find further improvements to keep abreast to the latest trends in jigs and fixtures industry. 
- The further study recommended for other researchers to replicate on a bigger scale using different methods concerning setting, clamping, and to release of workpieces after welding or tacking process.

\section{Acknowledgment}

The research titled "Multi-Angle Welding Jig" has applied for its patent with a number 1/2017/000352 on December 14, 2017. Hence a deep appreciation is given to the ISAT U President, Dr. Raul F. Muyong, Vice-President for Research and Extension, Dr. Carmelo V. Ambut and research adviser, Dr. Karlo S. Sira.

\section{References}

American Iron and Steel Institute (AISI)

Carlson, G. A. (2011) Error Uncertainty. Retrieved on November 5, 2016, from http://www.ece.rochester.edu/courses/ECE111/error_uncertainty.pdf

Deppert, W. \& Stoll, K. (1994). Pneumatische Steuerungen (Pneumatic Control Systems), 10th edition, published by Vogel Verlag, Würzburg 1994

De Vogt. H. J. (1954). Welding Clamp. Patent No. US2669957A. Retrieved March 11, 2015, from patentscope.wipo.int Griffin, I. H. (1994) Welding Process. $3^{\text {rd }}$ Edition.

Hesse, S. (2001) Clamping with Compressed Air and Vacuum by Festo AG \& Co. Ruiter Strasse 82 D-73734 Esslingen Blue Digest Automation.

International Electrotechnical Commission (IEC). Retrieved February 10, 2017, from https://ihsmarkit.com/products/iec-standards.html

Kellerson, K. W. (2008). Clamping Fixtures with Adjustable Assemblies. Patent No. US 8,113,497 B2. Retrieved March 11, 2015, from https://www.patents.google.com.

Leiseder, L.M. (1989). Pneumatische Spanntechnik (Pneumatic Clamping Technology), Published by Verlag Moderne Industrie, Landsberg 1989

National Institute of Technology Calicut (2017). Introduction to Jigs and Fixtures. Retrieved March 9, 2017, from http://www.nitc.ac.in

Němec, J. (2015). Design and Development of Measurement JIG System. Department of Machining Technology, Faculty of Mechanical Engineering, University of West Bohemia, 30100 Pilsen, Czech Republic. Retrieved February 10, 2017, from https://dspace5.zcu.cz/bitstream/11025/16127/1/Nemec.pdf

Society of Automotive Engineers (SAE) International

Swanson, D. (2011). Universal Clamping Block. Patent No. US 20120267839A1. Retrieved March 11, 2015, from https://www.patents.google.com.

Tierney, P. R. (1955). Corner Clamp. Patent No. US19522323260A. Retrieved March 11, 2015, from patentscope.wipo.int

Trewhella, G. W. (1939). The Design of Jigs and Fixtures for Machine Tools. Victorian Institute of Engineers. University of Melbourne. Retrieved March 11, 2016, from http://hdl.handle.net/11343/11343/24814

Wong, H. (2005). Z-bars. Patent No. US6,860,475. Retrieved March 11, 2015 from patentscope.wipo.int

Zhang, G., \& Hocken, R. (2008). Improving the Accuracy of Angle Measurement in Machine Calibration. CIRP Annals-Manufacturing Technology, 35, 369-372. http://dx.doi.org/10.1016/S0007-8506(07)61908-8

\section{Bio note:}

ERNIE A. DAITAO is an associate professor of Iloilo Science and Technology University, La Paz, Iloilo City, Philippines, 5000, erniedaitao@yahoo.com. His line of interest is on mechanical technology. Presently, he is the head of the Mechanical Technology Department. 